\title{
Optical Coherence Tomography for Examination of Parchment Degradation
}

\author{
Michalina Góra, ${ }^{1}$ Michael Pircher, ${ }^{2}$ Erich Götzinger, ${ }^{2}$ Tomasz Bajraszewski, ${ }^{1}$ Matija Strlic, ${ }^{3}$ \\ Jana Kolar, ${ }^{4}$ Christoph K. Hitzenberger, ${ }^{2}$ and Piotr Targowski ${ }^{1}$ \\ ${ }^{1}$ Institute of Physics, Nicolaus Copernicus University, ul. Grudziadzka 5, 87-100 Torun, Poland \\ ${ }^{2}$ Centre for Biomedical Engineering and Physics, Medical University of Vienna, Waehringerstr. 13, A-1090 Vienna, Austria \\ ${ }^{3}$ Faculty of Chemistry and Chemical Technology, University of Ljubljana, Aškerčeva 5, SI-1000 Ljubljana, Slovenia \\ ${ }^{4}$ National and University Library, Turjaška 1, SI-1000 Ljubljana, Slovenia
}

Received 20 September 2006; Revised 20 November 2006; Accepted 22 November 2006

Recommended by Costas Fotakis

\begin{abstract}
A novel application of Optical Coherence Tomography utilizing infrared light of $830 \mathrm{~nm}$ central wavelength for non invasive examination of the structure of parchment, some covered with iron gall ink, is presented. It is shown that both the parchment and the ink applied are sufficiently transparent to light of this wavelength. In the study, Spectral OCT (SOCT) as well as Polarisation Sensitive OCT (PS-OCT) techniques were used to obtain cross-sectional images of samples of parchment based on scattering properties. The second technique was additionally employed to recover the birefringence properties and the optical axis orientations of the sample. It was shown that freshly produced parchment exhibits a degree of birefringence. However, this property declines with ageing, and samples of old parchment completely depolarise the incident light.
\end{abstract}

Copyright (C) 2006 Michalina Góra et al. This is an open access article distributed under the Creative Commons Attribution License, which permits unrestricted use, distribution, and reproduction in any medium, provided the original work is properly cited.

\section{INTRODUCTION}

For more than a millennium, iron gall ink was among the most frequently used inks in Western civilization [1]. Some of the most important artworks by Rembrandt, J. S. Bach, Leonardo da Vinci, Victor Hugo, or Hans Andersen, to name but a few, were written or drawn with it. In general, the ink was used on many writing materials, very often on paper, but also on papyrus, parchment or vellum, for example, the Book of Kells, a medieval manuscript of extraordinary beauty and importance.

While many different ink recipes have been passed down to us, this ink consisted of three main ingredients: vitriol (predominantly iron(II) sulphate), oak galls (from which gallotannins were extracted) and binder (gum Arabic). Once applied, the ink rapidly turned from almost colourless to blue.

However, during ageing, the colour of iron gall inks continuously changes, mirroring the chemical processes taking place. Namely, the first-formed blue ink is chemically unstable and in addition, the ink components, mainly acids and iron ions, induce degradation of the support [2]. With time, the ink and support degradation products prevail and lend the ink its brown appearance, typical of many historical documents. However, the degradation process is an on-going one, and eventually the support may be corroded through its entire thickness, which may lead to extensive loss of both material and information.

It is therefore vital that we be able to detect and analyse the degradation processes, and whereas there are a number of analytical methods used in studies of paper degradation $[1,3]$, analysis of parchment remains difficult due to its inhomogeneity and complex structure. Collagen fibres in parchment undergo degradation, which eventually leads to almost complete loss of fibre structure. At this stage, if in contact with water, a gelatinous substance is formed and the original parchment mechanical properties are lost.

Analysis of parchment usually involves methods based on visual and microscopic, as well as chemical and physical, techniques [4]. Most often used are thermal analytical methods and X-ray diffraction. Microthermal analysis has been used to obtain information on the topography and thermal conductivity of sample areas of $100 \mu \mathrm{m}$ [5]. The $\mathrm{X}$-ray diffraction of collagen has provided information on 


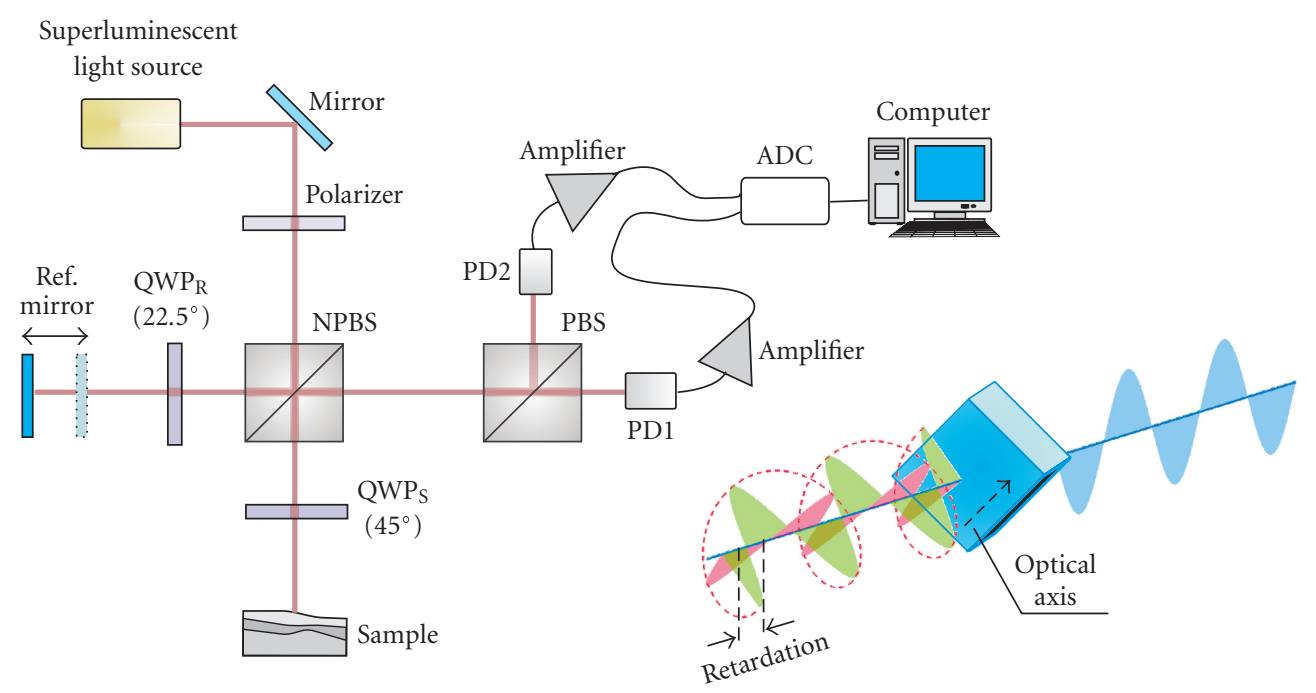

FIGURE 1: Schematic of the $0.83 \mu \mathrm{m}$ PS-OCT system (QWP—quarter wave plate, NPBS—nonpolarizing beam splitter, PBS—polarizing beam splitter, $\mathrm{PD}$ - photodetector, ADC—analogue to digital converter, REF. MIRROR—reference mirror).

the molecular organization of individual collagen molecules, while small angle X-ray diffraction has been used as a means of monitoring changes in the physical organisation of collagen within a parchment sample [6]. Differential scanning calorimetry (DSC) and thermogravimetry (TGA) were employed to study collagen temperature denaturation, and these results were confirmed by small angle X-ray scattering [7]. $\mathrm{X}$-ray diffraction was also used to study changes in the axial packing of collagen molecules due to dehydration [8]. The mechanical behaviour of parchment through its shrinkage temperature has been described by Cohen et al. [9]. All these methods concentrate on determination of specific chemical or mechanical bulk parameters referred to the whole thickness of the material. Here, we present a record of the first attempt to use optical coherence tomography for nondestructive in situ structural analysis of parchment.

\section{EXPERIMENT}

Parchment is a particularly difficult material to study due to its complex inhomogeneous structure. Infrared optical coherence tomography (OCT) at around $800 \mathrm{~nm}$ is well suited to this application, since both the parchment and the ink absorb light of these wavelengths rather moderately. A more detailed description of the OCT method can be found elsewhere in this volume [10]. Briefly, the method utilizes the interference of light of high spatial coherence (to ensure high sensitivity of imaging) together with very low temporal coherence (to increase in-depth resolution). To reveal the internal structure of the object a narrow beam of such light penetrates it and is scattered from structural elements. This scattered light is collected back by the same optics and then brought to interference with a reference beam in a Michelson interferometer. The positions of scattering centres or interfaces inside the object along the beam (an A-scan) is recovered from the detected signal. A crosssectional image of the material (B-scan) is compiled from adjacent A-scans.

\section{MATERIALS AND METHODS}

In this study, two OCT instruments were used: a spectral OCT system (also described in detail in this volume [11]) utilizes a light source of $835 \mathrm{~nm}$ central wavelength and a bandwidth of $50 \mathrm{~nm}$. This leads to a theoretical axial resolution of $6 \mu \mathrm{m}$ in the medium, of refractive index 1.5. The transverse resolution was $15 \mu \mathrm{m}$. The second OCT system, a time-domain polarization sensitive OCT (PS-OCT) system (Figure 1), was commissioned in the Centre for Biomedical Engineering and Physics of the Medical University of Vienna [12]. This instrument, in addition to the ordinary OCT images showing distributions of scattering centres, is also capable of imaging the distribution of retardations and optical axis orientations. These last two parameters describe the birefringence of the sample [13]. In such a time-domain instrument, in-depth scanning is accomplished by translation of the reference mirror. A polarizer and quarter-wave plate (QWP $45^{\circ}$ ) in the object arm convert the source beam into a circularly polarized one. After scattering in a nonbirefringent sample, the light is still circularly polarized, but if in its path within the sample there are some birefringent regions, the emerging light is elliptically polarized. This light is directed to the detecting arm, where it is spit into two orthogonally plane-polarized components which interfere with corresponding components returning from the reference arm. Simultaneous balanced detection of these two interference signals permits recovery of three images (see Figure 3 in Section 4): the intensity representation, which is equivalent to the image obtained from the ordinary OCT instrument, delineates the distribution of scattering centres along the 

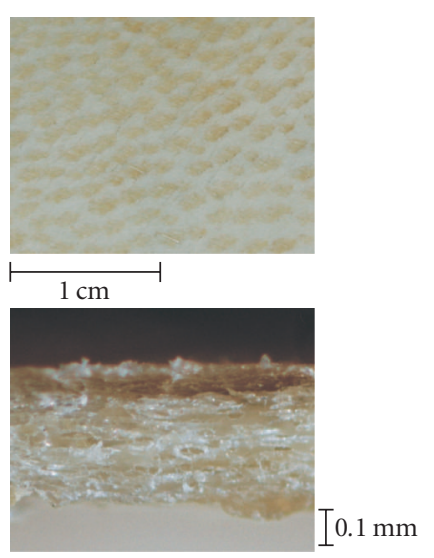

(a)
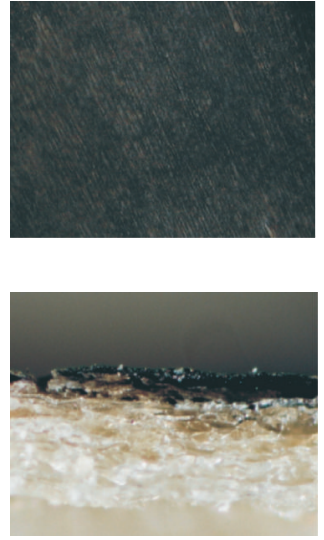

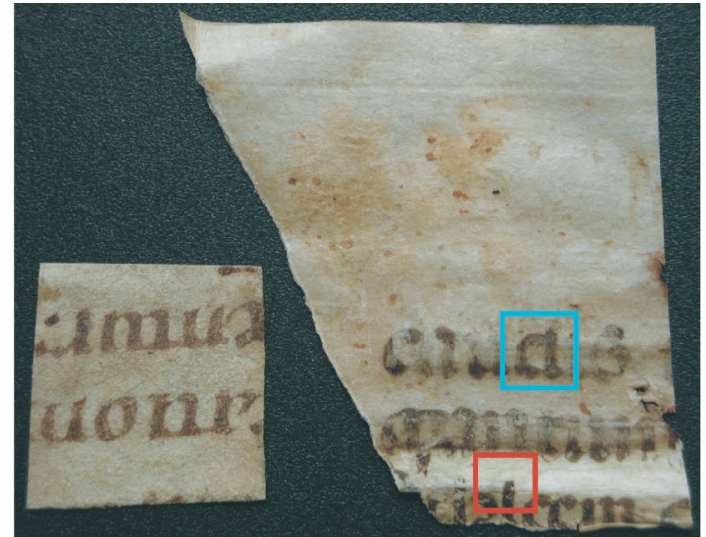

(b)

FIGURE 2: Samples used for examination: (a) preliminary samples and their cross-sectional views—on the right: sample covered with iron gall ink; on the left: a reference sample without ink; (b) samples of historical parchment with gall ink inscriptions.

probing beam; the retardation and optical axis orientation images characterize the polarization properties of the sample. Briefly, the retardation image reflects the phase difference between the two orthogonal polarization components, while the optical axis orientation image defines their orientation in space (see the insert in Figure 1 for an explanatory example). The resolution of this instrument is similar to that of the SOCT one.

Polarization-sensitive OCT has been used for examination of human skin for several years [14]. As revealed by Pierce et al. [15], the double-path retardation rate varies from 0.25 to $0.6 \mathrm{deg} / \mu \mathrm{m}$ in human skin, depending on its location. The authors point to collagen as the major component of skin responsible for its birefringence. Three dimensional PS-OCT images of human skin have been presented by Pircher et al. [16]. Their results reveal the birefringent nature of the stratum corneum-the outermost layer of the epidermis.

It is reasonable to assume that similar birefringence might be observed in parchment, because it is also composed largely of collagen fibres. However, many factors during the processing of skin to parchment may influence this property. Nevertheless, it is worthwhile to investigate whether or not parchment may retain some ability to polarize light. PS-OCT was used to check this hypothesis. Two kinds of sample were employed in this study:

(i) artificially degraded samples of contemporary parchment (Figure 2(a)),

(ii) fragments of an old manuscript of unknown origin and date (Figure 2(b)).

Samples of calfskin $(\sim 0.35 \mathrm{~mm}$ thick) were taken for preliminary study. Although skin, like parchment, is a very inhomogeneous material, we tried for these studies to select a part of the skin which had no macroscopically noticeable features to ensure that all the samples we prepared were as similar as possible. The samples were further processed by applying iron gall ink (composition as in [17]), and exposing the sample to accelerated degradation for 3 weeks at $80^{\circ} \mathrm{C}, 65 \%$ relative humidity. It is as yet unsure to what extent this treatment correlates with natural ageing of parchment. However, it is known that heating parchment to an elevated temperature promotes its chemical degradation, and our primary aim was to investigate the differences between degraded and original material.

Fragments of the historical parchment of unknown origin $(0.13 \div 0.18 \mathrm{~mm}$ thick $)$ were supplied by the National and University Library of Slovenia.

\section{RESULTS AND DISCUSSION}

All samples were investigated with both instruments, and representative results are shown.

Figure 3 displays intensity profiles (top row), retardation (middle row), and optic axis orientation images (bottom row). In the intensity images, backscattered intensity is plotted as a function of position on a logarithmic scale. Illumination is from above. In the fresh sample (left column), a highly reflective superficial layer is observed, followed by a hypo-reflective (dark) layer and a stronger backscattering layer. Zero or low retardation is observed in the topmost layer (blue colour in the retardation image), while the colour transition, via green to yellow, indicates some birefringence in the deeper layers. Also in the deeper layers, a predominating range of optic axis orientation is observed (yellow-green to orange). In the degraded sample without ink (middle column), the hypo-reflective layer beneath the surface is very shallow, and the material appears to have a higher birefringence (steeper transition from blue to yellow with depth). The degraded sample with ink (right column) seems to have a structure with properties in between those of the other samples.

The results obtained with the model artificially degraded samples were verified with the historical samples of 


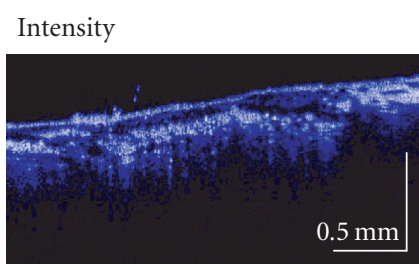

Retardation

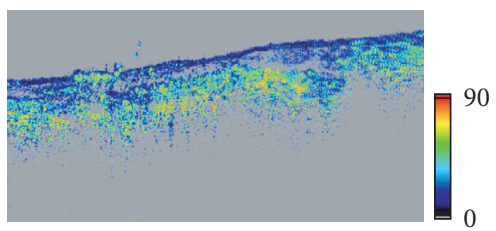

Axis orientation

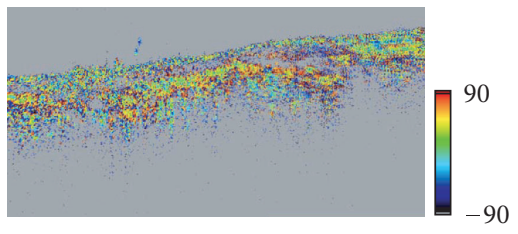

(a) Fresh sample with ink applied.
Intensity

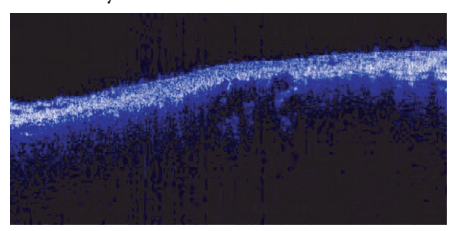

Retardation

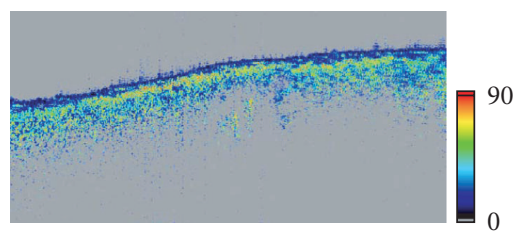

Axis orientation

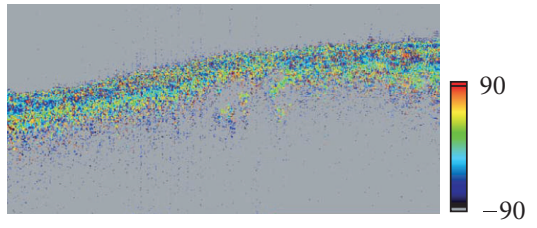

(b) Samples degraded at $80^{\circ} \mathrm{C}, 65 \%$ relative humidity for 3 weeks without ink applied.
Intensity

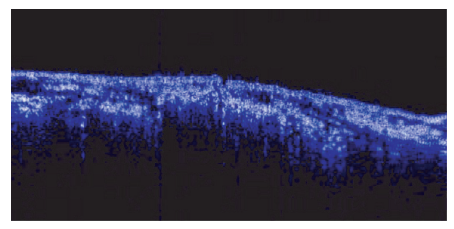

Retardation

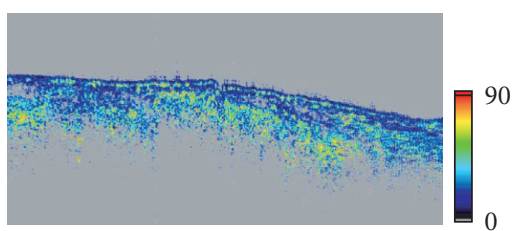

Axis orientation

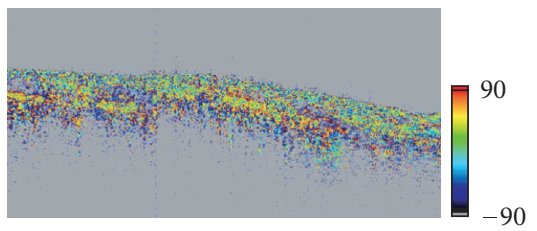

(c) Samples degraded at $80^{\circ} \mathrm{C}, 65 \%$ relative humidity for 3 weeks with ink applied.

FIGURE 3: PS-OCT tomograms of parchment samples obtained before and after artificial ageing. All images are presented on the same scale. It can be seen that the fresh sample shows stronger birefringence.

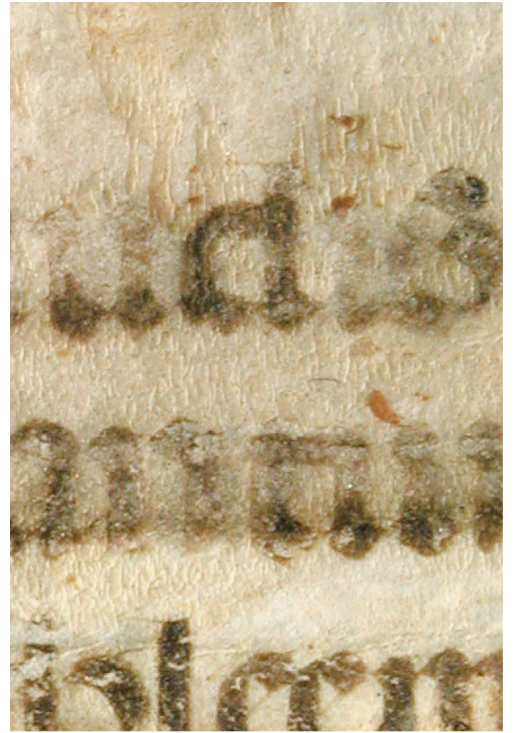

FIGURE 4: Macro photograph of the sample of historical parchment. Traces of water damage are visible.

parchment (Figure 2(b)). These items carried traces of fire and water spillage (Figure 4). The SOCT tomograms were taken across areas containing letters (squares in Figures 2(b), and 5). PS OCT examination (not shown) reveals complete depolarization of backscattered light.
As can be seen from the tomograms in Figure 5, this sample of parchment reveals much less structural details than the model one under OCT examination. It is not yet conclusive as to whether or not this feature is due to the age of the sample or to its particular properties. En-face images (Figures $5(\mathrm{a}), 5(\mathrm{c}))$ are obtained from OCT data by integration of the signal over the whole depth of imaging. Due to the transparency of iron gall ink to the light used, the letter "a," well defined in the original parchment, is hardly visible, if at all, in Figure 5(a), and is outlined for better differentiation. Much more visible are water stains (dark areas), in which regions the tomograms indicate a thick, homogenous layer (possibly of glue) at the surface (Figure 5(b)).

The analysis of the tomograms shown in Figure $5(\mathrm{~d})$ is more conclusive, due to the fact that water stains cover only the upper part of the area examined, and not interfere with areas covered by ink. Thus, it can be seen that the areas covered by ink are a little more textured than their surroundings (compare Figure 5(d)3 and Figure 5(d)4). This may indicate some structural change caused by the ink.

\section{CONCLUSIONS}

Optical coherence tomography at around $800 \mathrm{~nm}$ is capable of imaging the internal structure of parchment. For this wavelength, due to sufficient transparency of the ink thereon, it is possible to observe nondestructively the degradation of historical parchment below iron gall ink writing for the first 


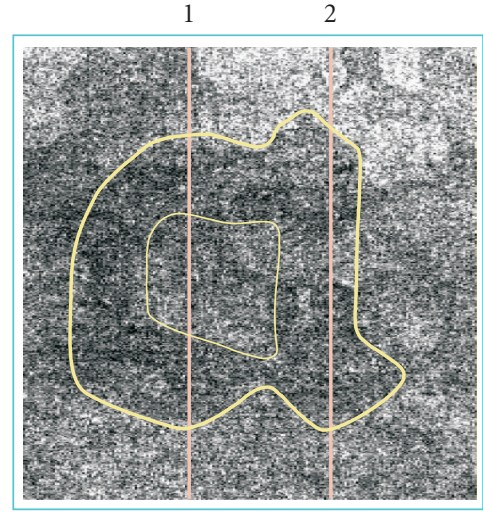

(a)
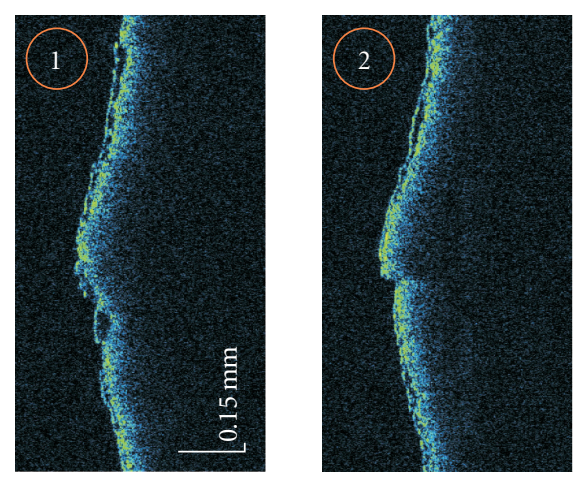
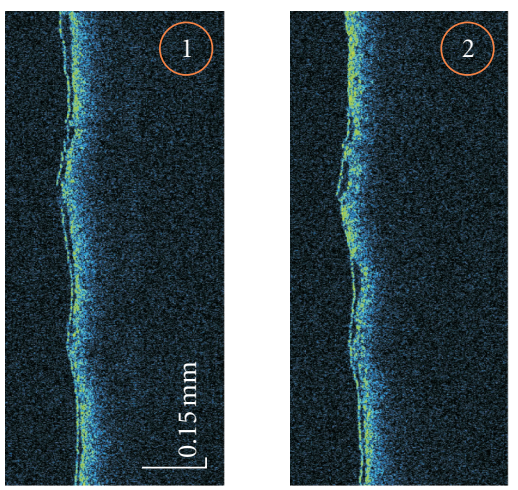

(b)
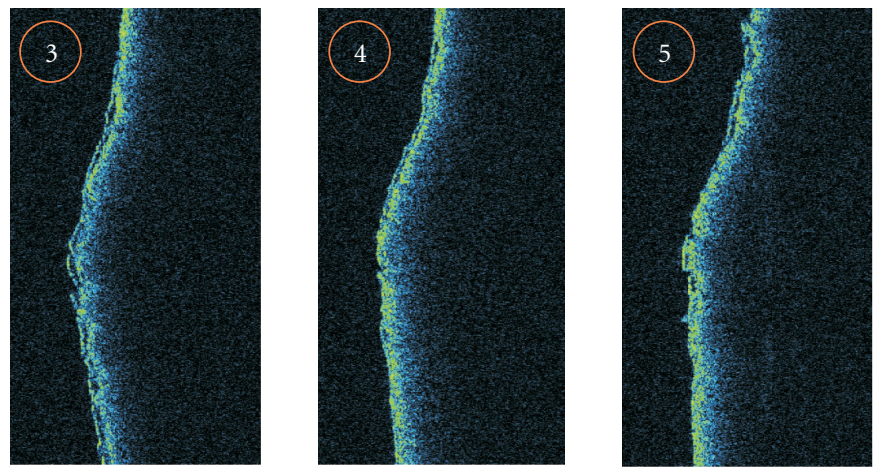

(d)

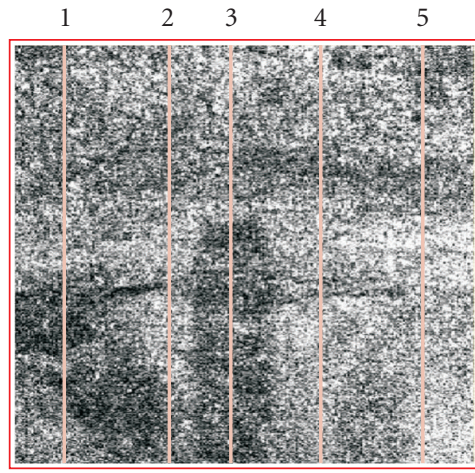

(c)

FIGURE 5: SOCT tomograms of samples of old parchment. Lines $(a, c)$ indicate position of OCT images (c, d, resp.). Illumination is from the left.

time. Some evidence of structural degradation under the ink layer has been found.

Additionally, it was shown that freshly produced parchment exhibits some birefringence. However, this property declines with degradation, and samples of old parchment completely depolarize the incident light.

This last finding as well as the range and interpretation of the structural effects caused by the presence of the ink need further investigation.

\section{ACKNOWLEDGMENTS}

Financial support from the Oesterreichische Akademische Austausch-dienst (OEAD) and the Polish Ministry of Science (joint project 6/2005/2006 and research project 2 H01E 025 $25)$ is gratefully acknowledged. The fifth author acknowledges the support of the Slovenian Research Agency (programme P1-0153). The fifth and sixth authors also acknowledge the support of the Ministry of Higher Education, Science and Sport of Slovenia, project Eureka E!3843.The fourth author gratefully acknowledges the support of a Foundation for Polish Science Scholarship for young researchers. The authors gratefully acknowledge the assistance of Dr. Z. Rozłucka, who made the cross-sectional photographs for
Figure 2(a). The authors wish to thank Dr. Robert Dale for many valuable discussions.

\section{REFERENCES}

[1] J. Kolar and M. Strlic, Iron Gall Inks. On Manufacture, Characterisation, Degradation and Stabilisation, National and University Library, Ljubljana, Slovenia, 2006.

[2] J. Kolar, A. Štolfa, M. Strlic, et al., "Historical iron gall ink containing documents - properties affecting their condition," Analytica Chimica Acta, vol. 555, no. 1, pp. 167-174, 2006.

[3] M. Strlic and J. Kolar, Ageing and Stabilisation of Paper, National and University Library, Ljubljana, Slovenia, 2005.

[4] R. Larsen, Microanalysis of Parchment, edited by R. Larsen, Archetype, London, UK, 2002.

[5] M. Odlyha, N. S. Cohen, G. M. Foster, A. Aliev, E. Verdonck, and D. Grandy, "Dynamic mechanical analysis (DMA), ${ }^{13} \mathrm{C}$ solid state NMR and micro-thermomechanical studies of historical parchment," Journal of Thermal Analysis and Calorimetry, vol. 71, no. 3, pp. 939-951, 2003.

[6] C. J. Kennedy, K. Nielsen, L. Ramsay, and T. J. Wess, "Analysis of collagen structure in parchment by Small angle X-ray diffraction," Fibre Diffraction Review, vol. 11, pp. 117-118, 2003.

[7] D. Fessas, M. Signorelli, A. Schiraldi, et al., "Thermal analysis on parchments I: DSC and TGA combined approach for heat 
damage assessment," Thermochimica Acta, vol. 447, no. 1, pp. 30-35, 2006.

[8] T. J. Wess and J. P. Orgel, "Changes in collagen structure: drying, dehydrothermal treatment and relation to long term deterioration," Thermochimica Acta, vol. 365, no. 1-2, pp. 119-128, 2000.

[9] N. S. Cohen, M. Odlyha, and G. M. Foster, "Measurement of shrinkage behaviour in leather and parchment by dynamic mechanical thermal analysis," Thermochimica Acta, vol. 365, no. 1-2, pp. 111-117, 2000.

[10] P. Targowski, M. Góra, and M. Wojtkowski, "Optical Coherence Tomography for Artwork Diagnostics," in this volume.

[11] M. Góra, P. Targowski, A. Rycyk, and J. Marczak, "Varnish ablation control by Optical Coherence Tomography," in this volume.

[12] M. Pircher, E. Götzinger, R. Leitgeb, and C. K. Hitzenberger, "Transversal phase resolved polarization sensitive optical coherence tomography," Physics in Medicine and Biology, vol. 49, no. 7, pp. 1257-1263, 2004.

[13] C. K. Hitzenberger, E. Götzinger, M. Sticker, M. Pircher, and A. Fercher, "Measurement and imaging of birefringence and optic axis orientation by phase resolved polarization sensitive optical coherence tomography," Optics Express, vol. 9, no. 13, pp. 780-790, 2001

[14] C. E. Saxer, J. F. De Boer, B. Hyle Park, Y. Zhao, Z. Chen, and J. S. Nelson, "High-speed fiber-based polarization-sensitive optical coherence tomography of in vivo human skin," Optics Letters, vol. 25, no. 18, pp. 1355-1357, 2000.

[15] M. C. Pierce, J. Strasswimmer, B. Hyle Park, B. Cense, and J. F. De Boer, "Birefringence measurements in human skin using polarization-sensitive optical coherence tomography," Journal of Biomedical Optics, vol. 9, no. 2, pp. 287-291, 2004.

[16] M. Pircher, E. Götzinger, R. Leitgeb, and C. K. Hitzenberger, "Three dimensional polarization sensitive OCT of human skin in vivo," Optics Express, vol. 12, no. 14, pp. 3236-3244, 2004.

[17] J. Kolar and M. Strlic, "Evaluating the effects of treatments on iron gall ink corroded documents: a new analytical methodology," Restaurator, vol. 25, no. 2, pp. 94-103, 2004. 